\title{
EL DERECHO DE INTERÉS PÚBLICO Y LA INTERSUBJETIVIDAD DE LAS RELACIONES SOCIO-JURÍDICAS. PROFANANDO EL DETERMINISMO NORMATIVO-FORMALISTA*
}

The Public Interest Law and the Intersubjectivity of the Socio-Juridical Relations. Desecrating the Normative-Formalist Determinism

\author{
ALEX RODRIGO Coll ${ }^{* *}$ \\ Unicatólica
}

\section{RESUMEN}

El normativismo formalista descalifica cualquier pretensión explicativa del derecho que comprometa el objeto de su estudio más allá de la norma jurídica. Comprender el derecho como una disciplina desligada de compromisos morales es un imperativo de su cualificación científica. Sin embargo, es ingenuo desconocer el rol que el derecho desempeña en las transformaciones sociales donde las composiciones holísticas sobrepasan el alcance normativista. Esta es solo una de sus aristas. Este artículo se propone aproximar como un conato conceptualizante, al derecho de interés público como una especialidad no normativista del derecho que integra la disciplina a la deconstrucción constructiva social interdisciplinar. Que como medio, desde los ámbitos político, social y jurídico, dispone la interacción entre los agentes-actores y los factores vinculados a los procesos de la arquitectura social.

\section{PALABRAS CLAVE}

Derecho, interés público, intersubjetividad

\section{ABSTRACT}

The formalist normativism disqualifies any explanatory pretension of the law that compromises the object of its study beyond the legal norm. Understanding the law as a discipline detached from moral commitments is an imperative of its scientific qualification. However, it is naive to ignore the role that law plays in social transformations where holistic compositions go beyond the normative scope. This is just one of its facets. This article aims to approximate as an attempt to conceptualize the public interest law as a non-normative specialty of law which integrates the discipline to social interdisciplinary constructive-deconstruction. That as a means from the political, social and legal spheres, it arranges the interaction between actors-agents and factors linked to the process of social architecture.

\section{KEYWORDS}

Law, Public Interest, Intersubjectivity

\section{Introducción}

La investigación científica según Bunge ${ }^{1}$ no siempre procura un conocimiento objetivo, como las ciencias formales que en la mayoría de las veces no dan cuenta ni se ocupan de los hechos sino de entes ideales (son racionales, sistemáticas y verificables, pero no objetivas). A

\footnotetext{
* Artículo resultado del Proyecto de Investigación titulado “Diseño del Consultorio Jurídico del Programa de Derecho de la Unicatólica: Hacia una gestión pública y privada del conocimiento jurídico, socio-jurídico e interdisciplinar", financiado por Unicatólica en desarrollo de la "V Convocatoria interna de proyectos de investigación -2018-2019-". Inicio: 08-08-2018, finalización: 08-08-2019.

** Abogado, Magíster en Derecho con énfasis en derecho público. Docente del Programa de Derecho de la Fundación Universitaria Católica Lumen Gentium. Líder del Grupo de Investigación en Derecho y Ciencias Políticas - Unicatólica. Investigador del grupo de Investigación Lumen Humanitas - Unicatólica. Correo electrónico: acoll@unicatolica.edu.co. Santiago de Cali, Valle del Cauca, Colombia.

${ }^{1}$ BUNGE (2018), pp. 6-7.
} 
menudo no exigen como elemento a priori identificar el objeto de estudio, sino que lo construyen en el decurso investigativo. Otras veces los procesos de formación del conocimiento científico no reclaman que $a b$ initio de la investigación se desarrolle la definición de su objeto de estudio; se puede partir de descripciones tenues que en la medida del avance de la propia investigación afloran elementos para fortalecer su delimitación, su individualización y en general, su conocimiento. Así se intentará decantar si la importancia de la noción de derecho de interés público es de alcance semántico o praxeológico.

La dogmática jurídica de corte continental cimienta las funcionalidades del derecho desde el normativismo, donde fincan también su alcance científico. Sin embargo, las realidades actuales le exigen al derecho como medio reconocer la avanzada fáctico-científica y acrecentar su conocimiento en paralelo, además de integrar conformando un todo interrelacionado, los conocimientos útiles que aportan los diálogos interdisciplinares con los alcances jurídicos, aunque no necesariamente normativistas. El derecho de interés público es un concepto complejo de aparente significante normativo, aunque su significado sea maleable y dúctil, inclinado más hacia las funcionalidades prácticas que hacia las lingüísticas.

Se trata de generar desde el derecho las transformaciones necesarias para lograr la construcción de destinos sociales claros y proyectivos, a partir de los cuales se aperturen relaciones dialógicas que procuren la integración, en exceso, de los diversos actores-agentes en la consolidación de las sociedades democráticas y plurales que la actualidad reclama. Por lo anterior, antes de intentar una definición del concepto de derecho de interés público se menciona lo que en definitiva no es, incluyendo aquello que lo puede contener pero que no lo agota, identificando las funcionalidades del concepto en la transformación estructural jurídicopolítica y hasta actitudinal, desde la generación de espacios de interacción social. El derecho de interés público, se expone aquí, genera un conocimiento de las realidades sociales a partir de la indagación de las mismas permitiendo que la identificación descriptiva se exponga como nicho de generación de propuestas y acciones transformativas alejadas de una simple oferta social y atendiendo las demandas reales, como lo exponen, entre otros, Durkheim, Husserl y Cossio ${ }^{2}$. Aspectos que se identificaron a partir de una investigación teórica de carácter documental y apoyada en el método hermenéutico, consolidando así, el alcance crítico y la finalidad propositiva de la indagación.

Como lo sostiene Calvo "nada impide que se pueda plantear incluso la reflexión sobre la naturaleza del derecho a partir de fundamentos de tipo fáctico" ${ }^{3}$. De lo anterior se desprende que el derecho de interés público posee la finalidad de reavivar en el derecho las funciones descriptivas, críticas y creativas. Estas de las cuales ha sido privado por la vía del positivismo legislativo y el positivismo historicista, cuyo sentido se arraiga en dogmas instrumentales depurados de cualquier sentido moral por considerarlo metafísico y por lo tanto a-científico ${ }^{4}$, "quizás así salgamos finalmente, en el siglo XXI, del siglo XIX"5.

\section{Busilis de un concepto complejo e indeterminado}

\section{La irresolución del lenguaje}

Las variadas orientaciones teórico-explicativas y justificativas del derecho, como el realismo, el positivismo, el historicismo y la teoría tridimensional entre otras, asignan a los significados y a los significantes del lenguaje jurídico diversos alcances dentro de las múltiples funciones lingüísticas para guiar el desarrollo de la perspectiva teórica que defienden ${ }^{6}$. Para Copi

\footnotetext{
2 DURKHEIM (1986), pp. 39-40; HUSSERL (1997), pp. 24-25; COSSIO (1948), pp. 69-70.

${ }^{3}$ CALVO (2008), p. 203.

${ }^{4}$ ZAGREBELSKY (2011), pp. 67-69; GADAMER (1985), p. 80.

${ }^{5}$ CASANOVAS (1998), p. 26.

${ }^{6}$ CARRIÓ (1966), pp. 34, 64, 66, 71, 72.
} 
y Cohen ${ }^{7}$, el lenguaje posee de manera general - no restrictiva ni taxativa - tres funciones básicas, la informativa, la directiva y la expresiva. Cada una de estas funciones se complejiza en la medida de la vaguedad y/o de la ambigüedad de las palabras pues, estas poseen diversos campos de aplicación. Además, los significantes no poseen significados intrínsecos reveladores, sino que, tanto estos como aquellos - los significantes y los significados-, son convencionales asignativos. El lenguaje no es instintivo, biológico ni genético, sino imputativo ${ }^{8}$. Pueden ser imputaciones ad-hoc, explicitando las funcionalidades para las necesidades propias de la especialidad a la cual se destinan. También pueden ser imputaciones lingüísticas generales como cuando se recurre al contenido funcional implícito del lenguaje según sus asignaciones convencionales habituales - las del lenguaje natural-

Partiendo de presupuestos organizativos y estructurales del derecho objetivo de corte formalista, las especialidades normativas suelen compendiarse y rotularse con epítetos consecuentes con la materia que regulan, como el derecho de familia, el derecho penal, el derecho laboral o el derecho administrativo entre otros. El concepto "derecho", además de ser una noción de extensa discusión académica, si es examinado como prefijo, implica o sugiere prima facie, la adscripción del contenido a la pre-mencionada esfera normativista. No obstante, no toda noción jurídica se inscribe dentro de esta orientación teórica del derecho porque entre otras cosas, las sustancias y los fenómenos como las informaciones, los procesos cognoscitivos y los procesos de comunicación entre otros, son relativos y dependen del alcance que se les adapte o se les asigne por parte de los actores-agentes ${ }^{9}$ a través de las relaciones de interacción intersubjetiva.

La referencia al derecho de interés público no circunscribe como su significante lo sugiere, una especialidad jurídica formal dentro de la disciplina, no compromete una concepción simplemente jurídica. Paradójicamente asume la tarea de generar impacto y transformaciones sociales desde el derecho, sin comprometer y sin agotar su significado y su alcance conceptual como una noción de orientación teórico-explicativa y justificativa puramente normativista. Su alcance conceptual se encuentra guiado por las necesidades, por las aspiraciones y por las predilecciones colectivas en una organización social. Su trascendencia práctica afecta tantos ámbitos colectivos e individuales inquiera para acertar en las transformaciones necesarias en correspondencia con los fines trazados. Sobrepasa ampliamente los aspectos de técnica jurídica para adentrase en los ámbitos de la técnica social. En suma, sobre pasa la mera técnica ${ }^{10}$, para auscultar en las ciencias y para servirse de estas, prevalentemente y no de manera limitativa, de las ciencias sociales y humanas.

Aunque las palabras que integran el concepto - derecho de interés público- lo insinúan, no se trata como ya se mencionó, del cumplimiento de reglas de procedimiento o de protocolos procesuales jurídicos que orienten el desenlace resolutivo de una problemática, aun cuando requiera de aquellos. Tampoco así de guisas, ritos o formulismos que ordenen los procesos cognoscitivos de los intríngulis y las bifurcas sociales, aunque también se valga de estos. Va más allá. El derecho de interés público inquiere la integración dialógica ${ }^{11}$ entre aquellas disciplinas junto con sus técnicas insertas, que proyecten un aporte para la deconstrucción constructiva o para la fortificación progresiva de las instituciones jurídico-políticas vigentes y venideras, respectivamente, en pro de reportar el mejor beneficio colectivo ${ }^{12}$. De igual forma sucede con los beneficios de la individualidad como elementos forzosos de interacción-intersubjetiva entre sujeto-comunidad. Compromete la acción constructiva a partir de la consideración y la relación con el otro ${ }^{13}$.

\footnotetext{
7 COPI y COHEN (2007), pp. 83-85.

${ }^{8}$ CONESA Y NUBIOLA (2002), pp. 21-22.

${ }^{9}$ SARTRE (1973), pp. 11-13.

${ }^{10}$ GIULIANI (1955), pp. 268-269.

${ }^{11}$ HABERMAS (1987), pp. 226-227; SORDÉ y OJALA (2010), p. 383.

${ }^{12}$ GALLIGAN (2007), pp. 11-12.

${ }^{13}$ SCHUTZ y LUCKMANN (2009), pp. 35-36.
} 
El derecho de interés público no relaciona un compendio normativo que líe una aplicación de subordinación heterónoma del individuo o del colectivo a una especialidad jurídica sustancial ni adjetiva. No regula una materia o una serie de conductas determinadas. Tampoco prescribe imposiciones, prohibiciones, prerrogativas ni facultades de los individuos o de las comunidades. Busca establecer conexiones constructivas entre los diversos frentes sociales y los gubernamentales para crear las trazas jurídico-políticas -instituciones discursivas, estructurales y operativas-, que viabilicen la consolidación del ideario democrático a partir de las necesidades y de las participaciones activas reales. García ${ }^{14}$ denomina esta funcionalidad como "eficacia simbólica del derecho", al referir que "la incidencia social del derecho depende, en alguna medida, de la capacidad para determinar las conductas por medio de la creación de ideas y no sólo por intermedio de la imposición de sanciones o del otorgamiento de facultades".

Las conexiones constructivas se traducen en la implementación de esquemas comunicativos que no se agotan en la realización discursiva como medio para la consecución de objetivos preestablecidos sectorizadamente. Por el contrario, racionalizan el proceso comunicativo como medio-diagnóstico de una realidad plurievaluada a partir de sus factores, prácticas, discursos, actores y agentes. Suscitan el acuerdo descriptivo, conclusivo y propositivo. Superan la función instrumental del discurso jurídico-político de poder, para la instauración del acto discursivo-comunicativo-dialógico social. Ontológicamente se proyecta así porque los propósitos y la realización, aunque algunas veces coincidan en sus consecuencias, no son nociones sinonímicas. Además, la luminosidad del detalle no está en su individualidad, sino que, desde ahí se proyecta para materializarse cuando el fragmento ocupa su lugar en la interacción con el conjunto ${ }^{15}$.

La indeterminación del concepto - derecho de interés público-, pareciera, enrostra su mayor debilidad. Surge en esa indeterminación el compromiso de una anarquía galimática y con esta, la abstracción manipulable de la escasez compositiva de elementos que arraiguen la objetividad. No obstante, es precisamente en esa amplia estructura conceptual en donde radica su jerarquía pues, la realidad de las relaciones sociales no es estática. Las personas, las conductas, los sucesos coyunturales, los discursos y la naturaleza entre otros elementos que confluyen en aquella, se transforman, presentan bifurcas que sorprenden y sobrepasan la capacidad planificadora y anticipativa ${ }^{16}$. La presencia de conceptos susceptibles de valoración y maniobra aplicativa se muestra ineludible.

\section{Los conceptos indeterminados}

La utilidad de los conceptos indeterminados se perfecciona en la capacidad de atender proyectiva y favorablemente aquellos aspectos imposibles de predecir a detalle último desde el proceso de planeación. Se materializa con la determinación más conveniente en el tiempo real y en la situación específica - durante la ejecución-, de tal manera que un sistema complejo de conceptos logra atender favorablemente las variables no previstas o no previsibles $a b$ initio, de cualquier proceso. En aspectos jurídicos los conceptos indeterminados sustentan la función integradora que supera la anacrónica, llana y vetusta función aplicativa del derecho en lo que al intérprete atañe para la resolución problémica. Sin embargo, dicha superación debe ser absolutamente escrupulosa para evitar que la función integradora se confunda con la función creadora ${ }^{17}$, cuidadosamente delimitada en los modelos con división orgánica y funcional del poder.

Los conceptos indeterminados como estándares decisionales proyectan una elasticidad configuracional que se reafirma o se desvanece, dependiendo de la doctrina medular del sistema social. No se trata de espacios de libertad sino de ámbitos de maniobra para la intervención,

\footnotetext{
${ }^{14}$ GARCÍA (1993), p. 3.

15 SARTRE (1973), p. 15.

${ }^{16}$ MORIN Y PAKMAN (1994), p. 73

${ }^{17}$ ARA (2004), pp. 108-109.
} 
para la adopción de decisiones y de cursos de acción. Como se analizaba con anterioridad, los problemas hermenéuticos y asignativo-convencionales del lenguaje producen en todas las nociones conceptuales "un halo de certeza y una zona de penumbra" 18 , que redundan en mayor o en menor proporción, en "algún grado de indeterminación"19. Las asignaciones conceptuales del lenguaje - las ad hoc y las generales-, afirman la aplicación reductiva de las zonas de obscuridad lingüística. Sin embargo, algunas veces por cuestiones de conveniencia y otras por imposibilidad material, no se puede prever hasta el más ínfimo detalle actuarial en los procesos de planeación-proyección, quedando con vasta amplitud -in abstracto- la indeterminación conceptual.

En aquellos sistemas en los que los procesos se encuentran limitados por la subsunción, los conceptos indeterminados son inoficiosos, contrarios y hasta peligrosos, pues proyectan una desnaturalización hermenéutica del poder cifrado. En aquellos sistemas en los cuales se privilegia la gestión autónoma-racional, los conceptos indeterminados arraigan la importancia del encuadre actuarial en el modelo. Permiten que a través del argumento justificativo -más allá del simplemente explicativo- ${ }^{20}$, se acredite la conveniencia de la configuracióndeterminada del alcance conceptual asignado - significado/significante- ${ }^{21}$. Sin embargo, la crítica y las prevenciones acerca de la reductio ad unum ${ }^{22}$ de las atribuciones impersonales, aunque menguadas permanecen.

\section{El derecho de interés público, más allá del formalismo jurídico}

El rol que desempeña el derecho en la sociedad actual a partir de su télesis, sus discursos, sus prácticas, sus agentes, sus actores y sus ámbitos de ejercicio, se encuentra revaluado con respecto al que se le asignó en los albores científico-jurídicos de la cultura greco-romana. Las transformaciones en los ámbitos económico, cultural y político entre otros, que trajo consigo la modernidad y la era tecnológica han transfigurado las formaciones mentales de los individuos y por contera, las de las comunidades. Esas transformaciones mentales humanas se constituyen en el substratum evolutivo, que marca las rutas configuracionales a las cuales obviamente, no escapa el derecho ${ }^{23}$.

La racionalidad instrumentalista actual del derecho no se limita a la imposición de reglas comportamentales con colofones de simple control social como sucedía en otrora, aunque esa sea la pretensión de algunos extremos ludistas. La reducción del objeto de estudio del derecho a la norma jurídica, partió de la depuración propuesta desde los esquemas positivistas, principalmente de la escuela analítica inglesa de Austin ${ }^{24}$ y de la teoría pura del derecho de Kelsen ${ }^{25}$. Las fórmulas fijaron los fundamentos de la separación conceptual y aplicativa entre el derecho y la justicia, de forma más precisa, entre el derecho y la moral, contra toda manifestación metadiscursiva esquematizadora del derecho. Sin embargo, han sido muchas las arremetidas filosóficas que ha debido enfrentar este paradigma, aquellas que han potencializado su declive con proposiciones como la tesis del derecho supralegal de Radbruch ${ }^{26}$, donde se reivindican los contenidos axiológicos en la teoría y en la praxis jurídicas. Lo propio hicieron otras corrientes teóricas como las sociológicas, las fenomenológicas-existencialistas y

\footnotetext{
${ }^{18}$ CASSAGNE (2013), p. 99.

${ }^{19}$ CASSAGNE (2013), p. 99.

${ }^{20}$ ATIENZA (1994), pp. 59-61.

${ }^{21}$ WROBLEWSKI (1988), pp. 866-867.

22 ZAGREBELSKY (1996), p. 118.

${ }^{23}$ MIR (2006), pp. 9-11.

${ }^{24}$ AUSTIN (2010), pp. 376-377.

${ }^{25}$ KELSEN (2009), pp. 45-55.

${ }^{26}$ RADBRUCH (1962), pp. 15-16.
} 
las realistas, con pensadores como Durkheim ${ }^{27}$, Husserl ${ }^{28}$ y Frank ${ }^{29}$, condensadas entre otros por Cossio ${ }^{30}$ con la teoría egológica del derecho.

El discurso jurídico actual reflexiona en torno a todo el sistema organizativo social, político y normativo. Compromete los dispositivos y las fuerzas que legitiman el compromiso y las luchas de una población comprometida con las problemáticas de la estructura social -inmediata y global-. Por lo tanto, la pureza ideológica y metodológica que propone el formalismo jurídico positivista se presenta como insuficiente. La naturaleza jurídica no es exclusivamente normativa, hermenéutica o tópica, sino que compromete una pluralidad de factores humanos -ideales y materiales - que componen las reflexiones y las proyecciones constructivas de las sociedades modernas, que cuestionan de forma permanente la función reguladora y legitimadora de las orientaciones jurídicas unívocas o puras. El denominado por algunos autores como escepticismo dogmático, que la observan como "extremadamente complicada y acuciosa [...] un juego de abalorios sin resultados" ${ }^{\prime \prime}$.

Desprovisto de objetivos axiológicos obligatorios en su contenido, el derecho de corte formalista ${ }^{32}$ que impera en las tradiciones jurídicas permeadas por el enfoque continental, privilegia la intervención meramente instrumental-mediática y específica, dejando la carga de la transformación social a otras disciplinas sociales como la ciencia política. La avidez depurativodogmática en esta corriente jurídica prioriza el obedecimiento a la orden conceptual de la norma sobre la realización prospectiva humana ínsita en la deontología jurídica. Esta se asume como un elemento exótico y exógeno al objeto de estudio para el desarrollo y conocimiento del derecho, aquella, como el elemento nuclear del dogmatismo jurídico.

Sin embargo, además de las ya mencionadas, algunas escuelas y estructuras de pensamiento como la magistratura democrática ${ }^{33}$, la egológica del derecho ${ }^{34}$, la del derecho libre ${ }^{35}$ y la jurisprudencia de intereses ${ }^{36}$, plantean grosso modo, que el derecho no puede ni debe agotarse en el señalamiento de protocolos estáticos para que el Juez y las personas en general, resuelvan a destajo las problemáticas sociales como se si se tratase de un programa automatizado. La télesis del derecho inscribe como meta primordial, la influencia transformativa y proyectiva de la vida. El concepto trasciende, se convierte, se exige.

La influencia transformativa de la vida navega entre las diversas luchas que se presentan por el logro de los intereses colectivos con nicho en las necesidades individuales. Esos intereses materiales e ideales, ontológicos y deontológicos, impactan en las estructuras sociales, políticas, culturales, religiosas e ideológicas entre otras, que marcan la ruta, también estructural del sistema jurídico. En tal sentido, se presentan aporías o al menos insuficiencias teórico-prácticas cuando la realidad ontológica del derecho desatiende el proceso de su formación o cuando este muestra un contenido desprovisto de estructuras axiales finalísticas que superen las estrictamente positivas-permisivas o negativas-prohibitivas, inconsecuentemente satisfechas en uno o en algunos de sus elementos sin una consideración o realización holística constante.

Un derecho positivo-formalista que elimina la conciencia del devenir social es un potencial elemento desarticulador de las estructuras sociales - de la sociabilidad-. El derecho entonces coexiste más allá del normativismo, "fluye por las venas y arterias de la vida social; circula impetuosamente en periodos de transformación social" ${ }^{37}$. No se agota en los códigos como mecanismos reguladores, sino que posee responsabilidades transformadoras. De arquitectura social.

\footnotetext{
27 DURKHEIM (1986), pp. 60-62.

${ }^{28}$ HUSSERL (1997), pp. 24-25.

${ }^{29}$ FRANK (1973), pp. 316-317.

${ }^{30}$ COSSIO (1948), pp. 69-70.

${ }^{31}$ ROXIN (2007), pp. 4-5.

32 KELSEN (2009), pp. 45 y ss.

${ }^{33}$ FERRAJOLI (1997), p. 6

${ }^{34}$ COSSIO (1948), pp. 69-70.

35 GÈNY (1919), pp. 15-16.

${ }^{36}$ GARCÍA (2011), pp. 218-219; HECK (2018), pp. 62-63.

${ }^{37}$ BOTERO (1997), p. 291.
} 
El derecho de interés público se amplía o se reduce, se simplifica o se complejiza, se apertura o se bloquea, se cierne o rompe paradigmas. Muta, no es estático. Persistentemente está dispuesto a la aprehensión valorativa para su mejor comprensión y gestión. El derecho de interés público depende epistemológicamente de la forma en que la sociedad apropia y aprehende el concepto y ontológicamente, de la realidad fáctica que acaece en cualquier estructura social. De forma consecuente, la dimensión genética del concepto se arraiga en la estructuración institucional y la dimensión aplicativa está determinada por la producción normativa, por la praxis judicial, por los desarrollos doctrinales y en general, por el activismo social. Ambas dimensiones están contenidas en procesos cíclicos determinadores de la dimensión conceptual descrita previamente que se arraiga en los intereses sociales axiológicamente identificados.

No se trata de una rama específica del derecho que se clasifica por sus insertos, como el derecho de familia, el derecho penal, el derecho laboral o el derecho administrativo entre otros. Su cualificación se arraiga en el sentir general que traza colofones, límites y medios permeados por la naturaleza social, donde las problemáticas de probable impacto masivo constituyen el interés público y en igual sentido el componente jurídico como medio-respuesta. El derecho de interés público no hace parte del archipiélago contentivo de las islas normativistas clasificadas en razón de sus materias, sino que se encuentra en todas, en algunas o en ninguna, si las necesidades sociales así lo inquieren. Unas veces para servirse de aquellas y otras para transformar sus estructuras y contenidos en una sociedad permeada por ordenaciones rígidas que dificultan la identificación de destinos comunes sin avasallar la identidad individual o minoritaria y el establecimiento de catálogos axiológicos atrayentes y aplicables a la universalidad.

\section{El derecho de interés público: entre la filosofía del derecho, la filosofía política y la filosofía social}

Al preguntarse si el derecho de interés público se encuentra marcado por las delimitaciones epistemológicas y gnoseológicas de la filosofía del derecho, de la filosofía política o de la filosofía social, la respuesta no puede ni debe ser unipolar o excluyente. Resulta impreciso recurrir al razonamiento retórico que se funda en las opiniones para decantar las conclusiones del alcance teórico-aplicativo de aquello que se pretende conocer y comprender -el derecho de interés público- . Se debe acudir al razonamiento analítico que se desprende desde la identificación a priori, de las proposiciones forzosas y propicias para el ejercicio racional ${ }^{38}$. Estas que son las resultas de las entidades teóricas, humanas e institucionales de la estructura social y que, por lo tanto, corresponde su análisis tanto a uno como a los otros extremos de la filosofía propuestos para comprender y conocer el concepto.

El estudio del derecho de interés público recurre a la filosofía del derecho porque es precisamente desde la comprensión de esta efigie a partir de donde se advierte el alcance jurídico en los procesos de la arquitectura social ${ }^{39}$. También así, las objeciones a este posible alcance. La filosofía del derecho no solo compromete el estudio del orden normativo como lo pretenden algunas de sus corrientes - las ius formalistas-, sino también, los cursos de acción individuales, los de la interacción social - elementos fenomenológicos-, las cosas materiales e inmateriales - las de la existencia misma- y al ser humano como actor-agente ${ }^{40}$. Los primeros a modo de objetos y el último como sujeto, ambos de derecho.

Desde los diversos matices que representan la mayor parte de las conceptualizaciones teóricas actuales del derecho - pro personae-, a este se le reclaman incluso, configuraciones provenientes de los ámbitos sociológicos. Se pretende que desde el derecho opere el amparo

\footnotetext{
${ }^{38}$ ALEXY (1989), p. 191.

${ }^{39}$ ZAGREBELSKY (1997), pp. 121-122.

${ }^{40}$ COSSIO (1964), p. 273.
} 
institucional, axiológico y normativo, de las inclinaciones, intereses, preferencias, deseos y demandas sociales. En la medida en que aquel se adapte a estas, le sobreviene su legitimidad. Se trata, en suma, de reivindicar en el derecho fundamentaciones filosófico-jurídicas, sociales, axiológicas y en general humanas, que líen en una relación de equilibrio los hechos sociales con las manifestaciones normativas, vinculando como criterios de la racionalidad a la necesidad, a la utilidad y a los potenciales gravámenes. Comprometer en sus desarrollos los aspectos de la ontología jurídica -el objeto de conocimiento empírico-jurídico-, de la lógica jurídica formal - cómo se piensa en la experiencia jurídica一, de la lógica jurídica trascendental -cuándo y para qué se conoce en la experiencia jurídica- y de la axiología jurídica - el deber ser de la experiencia jurídica- ${ }^{41}$.

El derecho de interés público también recurre a la filosofía política por comprometer esta, la comprensión de las relaciones de poder a partir de los varios elementos que confluyen en aquella. Los derechos, la justicia, la autoridad, el mercado, la libertad. Habermas sostiene que entendiendo la política como mecanismo participativo ciudadano en los procesos configurativos sociales "tiene la función de agavillar e imponer los intereses sociales privados frente a un aparato estatal que se especializa en el empleo administrativo del poder político para conseguir fines colectivos" ${ }^{\prime 2}$. A través de la filosofía política se razonan las causas, los fundamentos y los efectos del poder como medio para la consecución de los fines propuestos en una sociedad cualquiera. Apertura los espacios de dilución conceptual y práctica en las disputas actuales acerca de la sociabilidad y la individualidad, de la subjetividad y la intersubjetividad, de la redistribución y el reconocimiento ${ }^{43}$. En suma, para el caso presente a partir de la filosofía política se conocen los fundamentos explicativos y justificativos de lo que, desde el deber ser, se reconoce como el "interés público".

\section{Derecho}

La línea de aproximación conceptual desarrollada hasta ahora permite colegir la intención de desmarcar la definición del concepto "derecho de interés público" del perfil argumentativo y de fundamentación del derecho normativista como una corriente de la filosofía del derecho. Sin embargo, desmarcar no significa desconocer. El derecho de interés público no se opone al establecimiento de normas y a su acatamiento, por el contrario, se trata de uno de sus corolarios. Se opone a la limitación del derecho a la norma jurídica pues la función del derecho se materializa en la transformación de las estructuras institucionales para salirle al paso a las dinámicas sociales y a las coyunturas naturales. En esta tarea el derecho no puede ni debe constituirse como un nicho de conocimientos y de funcionalidades estanco que lo marginen de las realidades que procura abordar.

Atienza ${ }^{44}$ sostiene que la ubicuidad es una cualidad innegable del derecho pues no existe ámbito relacional humano que no pertenezca o que no esté atado a los lazos jurídicos. Añade que el apiñamiento normativo no es causa efectiva de una sociedad justa o de relaciones jurídicas con esta condición pues la producción normativa no agota lo que el derecho es ni para qué lo es. Así, el derecho es un producto humano, de necesario, aunque no obligado contenido contextual e histórico que aterriza como el medio más idóneo para aliviar las tensiones que se generan en la realidad de las relaciones intersubjetivas. Permite cristalizar idearios, propósitos, esquemas, proyectos, mecanismos, planes, prebendas, sanciones, entre muchos otros elementos que confluyen a la vida diaria y cuyos fundamentos provienen de contenidos disciplinares diversos que invitan al derecho de manera inevitable, al diálogo constructivojurídico no limitado por el normativismo habitual.

\footnotetext{
${ }^{41}$ COSSIO (1948), pp. 67-68.

42 HABERMAS (2005), p. 1.

${ }^{43}$ FRASER (2008), p. 85.

${ }^{44}$ ATIENZA (2001), pp. 40-41.
} 


\section{Interés público}

La referencia a la noción "interés" proyecta aquel conjunto de preferencias que una vez materializadas reportan algún grado de satisfacción a su destinatario. El "interés" no compromete necesariamente reflexiones morales ni enlaces teleológicos derivados de los mandatos de la razón objetiva. Comporta realizaciones volitivas mayoritariamente atadas a las complacencias. Para Kant, las personas pueden actuar por interés o interesarse en la actuación por colofones superfluos sin desvelos por las resultas medulares. A la primera clase de interés la denominó "interés práctico en la acción" y a la segunda "interés patológico en el objeto de la acción" ${ }^{45}$. El interés práctico se encuentra guiado por los imperativos de la razón (deber ser), donde el sujeto actuante despliega su curso de acción determinado por la reflexión volitiva que opta por lo bueno o por lo preferible. En el interés patológico el sujeto actuante se encuentra determinado por los dictados de la razón subjetiva, guiada por la complacencia (agradable a las sensaciones personales), sin que se comprometa necesariamente una inclinación hacia lo bueno o hacia lo preferible.

El "interés" tampoco vincula alcances conceptuales sinonímicos con la noción de "beneficio", sin embargo, aquellos no se presentan como conceptos excluyentes. Los intereses fluctúan entre las predilecciones, los deseos, las necesidades y hasta por las emociones. La satisfacción de un interés puede o no reportar un beneficio. A manera de ejemplo piénsese en un estadio social en el cual la acumulación desmedida de riquezas posee una importancia prevalente sobre la sostenibilidad del ambiente y de los recursos naturales. Tratándose de un territorio con abundantes reservas petrolíferas se decide explotarlas sin consideración diferente al acopio de capital económico. Al cabo de varios años los recursos hidrográficos se agotan luego de que sus fuentes sufrieran daños irreparables. Seguramente esta sociedad colmará sus intereses materiales con el coste de los desatinos ecológicos. Se trata de la tipología de interés patológico pues el compromiso de los cursos de acción está guiado por colofones sin beneficios sustanciales sino superfluos no favorecedores.

En el punto la disertación anterior permite plantear desde ya, la discusión con propósitos distintivos entre el interés público o general y el bien común. El interés general encierra prima facie, compromisos de funcionalidad, pragmatismo y eficiencia - racionalidad práctica de los fines-. Por su parte, el bien común integra componentes axiológicos-finalísticos - racionalidad práctica de los valores ${ }^{46}$. Sin embargo, como ya se mencionó pueden existir intereses que satisfagan con vasta importancia los valores sociales.

Hacia ese campo se proyecta el interés público en una sociedad democrática y pluralista. Hacia el establecimiento de inclinaciones y predilecciones colectivas que reporten beneficios comunes. La gestación de una "antipolítica" como nueva política que emerge "en la praxis emancipadora que partía de la responsabilidad por el otro" 47 . López sostiene que "cuando se hable de "interés público" siempre estará presente la cuestión de si ese "interés público" es algo objetivable o es una realidad relativa a un poder capaz (legitimado o no) para establecerlo como tal $^{\prime 48}$. Si bien es cierto los intereses son productos subyacentes de la individualidad subjetiva, nada impide que estos, al menos cuando se trate de lograr colofones colectivos derivados de la interacción intersubjetiva, sean determinados por imperativos de la razón objetiva que cristalicen el telos social tal y como lo inquiere la construcción de una política crítica.

El interés público obliga a abandonar las retóricas manipuladoras de la política abrasiva, las del dominio y las de la hegemonía, donde se explaya la estela considerativa que propone que las decisiones públicas se determinan de manera exógena y de espaldas a la comunidad a partir de las tensiones que generan las relaciones del capital transnacional ${ }^{49}$. Se propone establecer

\footnotetext{
${ }^{45}$ KANT (2007), p. 28.

${ }^{46}$ MACCORMIC (1990), pp. 11-12.

${ }^{47}$ DUSSEL, (2001), p. 11.

${ }^{48}$ LÓPEZ (2010), p. 125.

${ }^{49}$ PASTRANA (1988), pp. 32-33.
} 
un actuar crítico frente a la indiferencia y a la apatía social que someten a la población a destinos inciertos y extraños a sus particulares inclinaciones. Retoma aquellas prácticas aparentemente anacrónicas a partir de las cuales se reflexiona de manera abierta y crítica encontrando espacios emblemáticos como: (i) los participativo-comunitarios y representativos, desde los cuales se delibera y se legisla, (ii) los gubernativos, que rigen la toma de decisiones abiertamente democráticas y (iii) los jurisdiccionales, que materializan el control a partir de los cuales se constatan las coincidencias entre las disertaciones, las normativas y las decisiones, con los postulados regentes de dicha comunidad ${ }^{50}$. En términos de Pintos, "necesitamos descubrir nuevos conceptos que nos permitan generar y responder a la flexibilidad de las referencias" 51 .

\section{Intersubjetividad}

La conducta humana como substratum y expresión de la libertad individual constituye su cúspide valorativa en la proyección de la existencia misma. Humanismo trascendental ${ }^{52}$. Arremete axiológicamente contra un actuar avalorativo que consume el ciclo biológico y apertura un portal de posibilidades de interacción con otras conductas que representan también destinos individuales. Así, las conjunciones conductuales rutinarias y las circunstanciales generan fricciones y asociaciones derivadas de las múltiples disonancias y coincidencias teleológicas, respectivamente, entre los actores - causantes-y los agentes - que permiten, prohíben o se afectan- de los procesos conductuales. Estas relaciones configuran la intersubjetividad de las conductas humanas.

Las conductas en interferencia intersubjetiva como efectivamente son los cursos de acción que se despliegan en la interacción social, no poseen representaciones unívocas. Tampoco pueden ser categorizadas, valoradas ni calificadas de manera objetiva desconociendo las reflexiones del sujeto actuante ni las reflexiones de los sujetos vinculados por derivación a la actuación. Lo anterior significa que todos los cursos de acción comprometen tanto al actor como a los agentes - al sujeto causante y a aquellos que permiten, prohíben o se afectan con la actuación, por encontrase situados en el perímetro de la esfera consecuencial de la relación actuarial-. Estos compromisos individuales y colectivos lían sentimientos, preferencias, utilidades y destinos que condicionan las lecturas conductuales y marcan desde las peculiaridades, potenciales trazas para determinar la objetividad valorativa social. "Ni lo universal tiene valor y es llevado a cabo, sin el interés, el saber y el querer particular, ni los individuos viven como personas privadas meramente para esto, sin que, a la vez, quieran en y para lo universal y tengan una actividad consciente en este fin" 53 .

Las vinculaciones sociales de las conductas individuales generan en el ámbito material no en el metafísico-, consecuencias o imputaciones variadas, cuya objetividad se encuentra determinada por los sistemas normativos en cualquier estructura social actual. Se trata de lineamientos conductuales ex ante, que se configuran de forma exógena a los individuos a partir de las estructuras de poder institucionalizadas en la organización social. Sin embargo, la heteronomía como característica imputacional no compromete una oferta jurídica configuracional unidireccional. Se trata de establecer esquemas jurídico-políticos que integren la realización de los planes existenciales comunes, cooptados en consideración al individuo cualitativo y no exclusivamente cuantitativo, como normalmente sucede.

\section{Conclusiones}

Los conceptos que no se encuadran en una estructura formal de definiciones son vistos con escepticismo, se perciben como insuficientes para aportar claridad a las nebulosas de las

\footnotetext{
${ }^{50}$ RANCIÈRE (1995), pp. 2-4.

51 PINTOS (2004), p. 17.

52 SICHES (1939), p. 21.

${ }^{53}$ HEGEL y MARX (1968), p. 215.
} 
dinámicas sociales. La seguridad que arrojan las estructuras formales-materiales potencializan su importancia en el eficientismo. Es decir, en la capacidad aplicativa susceptible a la tangibilidad, aunque no así de la capacidad resolutiva. Es netamente funcionalista. Sin embargo, esa seguridad no está ligada per se, a algún grado de beneficio real. La inclinación del ser al diálogo interno y por efecto a la reflexión filosófica genera la necesidad habitual de preguntar contra toda respuesta alcanzada de modo que las concepciones explicativas meta-discursivas in abstracto, aportan las soluciones que las estructuras rígidas y materiales objetivas no satisfacen por insuficiencia. Se reclama la generación de nuevos conceptos y de nuevos alcances praxeológicos y semánticos cuyo avance permita responder adecuadamente a lo variable, a lo sorpresivo y en general, a lo complejo e innovador.

El derecho de interés público no es una ramificación normativista del derecho cuya denominación nace del vínculo entre las normas y las materias que se regula, como sucede en el derecho civil, en el derecho internacional, en el derecho canónico entre otros. Su denominación nace de la coherencia teleológica del derecho como un medio complejo que cimienta la estructura relacional social, que hace posibles tales relaciones intersubjetivas y que además debe ser protagonista de las transformaciones institucionales que exigen las inestables y veloces evoluciones del conocimiento humano y de las inesperadas reacciones y coyunturas naturales, donde se relega la paquidérmica institucionalidad estructural.

En el plano jurídico el alcance praxeológico de las entidades materiales $-y$ de las inmateriales por asociación lógica-, está enteramente ligado a los esquemas definitorios ideales asignativos. Un cuerpo material como producto de la naturaleza o como producto humano según corresponda, abraza su ontología jurídica, no por su precondición de realidad tangible, sino por la especial significación que se determina a partir de las realidades humanas. Las construcciones físicas como realidades tangibles y como productos humanos no poseen la condición empírica que se les reconoce desde dicha cualificación, sino por la asignación definitoria especial que se le estipula en la realidad humana. Son alcances conceptualespraxeológicos metadiscursivos, que subyacen en la necesidad de establecer funcionalidades útiles.

Los alcances mediáticos del derecho de interés público se encuentran determinados por su telos, no por sus trayectorias conceptuales que deben ser dinámico-variables, conforme lo son las estructuras sociales y los elementos que las describen y prescriben. El valor se encuentra en la praxeología que el significante sugiere más que en el significado que se le pueda asignar. La importancia es de alcance práctico y no de alcance conceptual, aunque este último se intente o se perciba como necesario. Algunos conceptos o instituciones jurídicas formales poseen la capacidad de guiar objetivamente las situaciones sociales, sin embargo, dicha formalidad en la mayoría de las veces desemboca en imposibilidades para el abordaje problémico, donde cobran fuerza, los conceptos y las instituciones que gozan de indeterminación conceptual, porque permiten ajustar los alcances a las medidas de las necesidades, respetando los principios y los valores medulares que sustentan un determinado sistema.

En el derecho de interés público subyace la necesidad de entrabar la interacción interdisciplinar, interinstitucional e intersectorial, como componentes de las estructuras sociales para la construcción de una política-antipolítica que devele ventajas comunes, interesada por la individualidad y la minoría sin agobiar a la colectividad y que, además reporte la consecución de los objetivos sociales trazados en coherencia, no solo con los intereses, sino necesariamente con los beneficios reales. Dicho de otra forma, el derecho debe suministrar espacios de investigación para la detección, identificación e individualización de problemas-soluciones-fines, de igual forma que suministrar medios y construir estructuras sociales que posibiliten y aseguren, respectivamente, tales destinos. Espacios a los cuales las áreas del derecho normativista no apuntan con suficiencia praxeológica ni ideal pues se encuentran relegados de su ámbito de injerencia y utilidad, en razón a la preponderancia formal, normativista y reguladora, donde se agota la disciplina. 
AleXY, ROBERT (1989): Teoría de la argumentación jurídica (Madrid, Centro de Estudios Constitucionales).

Ara Pinilla, IGNacio (2004): "Presupuestos y posibilidades de la doctrina de los conceptos jurídicos indeterminados", en: Anuario de filosofía del derecho (№ 21), pp. 107-124.

Atienza, Manuel (1994): "Las razones del derecho. Sobre la justificación de las decisiones judiciales”, en: Isonomía: revista de Teoría y Filosofía del Derecho (№ 1), pp. 52-69.

(2001): El sentido del Derecho (Barcelona, Editorial Ariel).

AUSTIN, JOHN (2010): Lectures on jurisprudence or the philosophy of positive law, 5 a edición (Londres, The Lawbook Exchange Ltd).

Botero Uribe, Darío (1997): “El derecho es la vida”, en: Giraldo Ángel, Jaime; Hoyos Vásquez, Guillermo; Martínez Caballero, Alejandro; Mayorga García, Fernando; Laverde Toscano, Eduardo; Monroy Cabra, Marco Gerardo; Noguera Calderón, Rodrigo; Plazas Vega, Mauricio Alfredo y Sánchez Botero, Esther, Hermenéutica jurídica: Homenaje al maestro Darío Echandía (Bogotá, Ediciones Rosaristas), pp. 291-297.

BUnGE, MARIO (2018): “La ciencia: su método y su filosofía”, en: Revista Laetoli (№ 1), pp. 6-74.

Calvo García, Manuel (2008): "Positivismo Jurídico y transformaciones del derecho", en: Almoguera Carreres, Joaquín, Estudios en homenaje al profesor Gregorio Peces-Barba (Madrid, Dykinson), volumen 2, pp. 201-222.

CARRIÓ, Genaro (1966): Notas sobre derecho y lenguaje (Buenos Aires, Editorial Abeledo Perrot).

CASANOVAS, POMPEU (1998): Las formas sociales del derecho contemporáneo: el nuevo ius commune (Barcelona, Repositorio de la Universitat Autónoma de Barcelona).

CASSAGNE, JUAN (2013): El acto administrativo. Teoría y régimen jurídico (Bogotá, Editorial Temis). CONESA, FrAncisco y Nubiola, JAIME (2002): Filosofía del lenguaje, 2ª edición (Barcelona, Editorial Herder).

COPI, IRVING Y COHEN, CARL (2007): Introducción a la lógica (México. Editorial Limusa).

Cossio, Carlos (1948): “Panorama de la teoría egológica del derecho", en: Revista de la Universidad Nacional (Vol. 13, № 13), pp. 66-94.

(1964): La teoría egológica del derecho y el concepto jurídico de libertad, 2ª edición (Buenos Aires, Editorial Abeledo Perrot).

DURKHEIM, ÉMILE (1986): Las reglas del método sociológico (Traducc. Ernestina de Champourcin, México, Fondo de Cultura Económica).

DUSSEL, ENRIQUe (2001): Hacia una filosofía política crítica (Bilbao, Desclée de Brouwer).

FERRAJOLI, LUIGI (1997): "Jurisdicción y democracia", en: Revista Jueces para la democracia (Vol. 29, № 1), pp. 3-9.

FRANK, JeROME (1973): Courts on trial: Myth and reality in American justice (Princeton, Princeton University Press).

FRASER, NANCY (2008): “La justicia social en la era de la política de identidad: redistribución, reconocimiento y participación”, en: Revista de trabajo (Vol. 4, № 6), pp. 83-99.

GADAMER, HANS (1985): "Fenomenología, hermenéutica, metafísica", en: Teorema, Revista internacional de filosofía (Vol. 15, № 1), pp. 73-80.

Galligan, DenIS (2007): Law in Modern Society (Oxford, OUP-Clarendon Law Series). 
García SALGAdo, MARÍA (2011): La jurisprudencia de intereses de Philipp Heck (Granada, Editorial Comares).

García VilLegas, MAURICIO (1993): La eficacia simbólica del derecho. Examen de situaciones colombianas (Bogotá, Ediciones Uniandes).

GÈNY, FRANÇOIS (1919): Méthode d’ interprétation et sources en droit privé positif - essai critique (Paris, Librairie générale de droit \& de jurisprudence).

Giuliani, Alessandro (1955): “¿Ciencia o técnica del derecho?”, en: Anuario de filosofía del derecho (№ 3), pp. 245-282.

HABERMAS, JÜRGEN (1987): Teoría de la acción comunicativa (Madrid, Taurus), volumen I.

(2005): "Tres modelos de democracia. Sobre el concepto de una política deliberativa", en: Polis Revista Latinoamericana (№ 10), pp. 1-9.

HECK, PHILIPP. (2018): El problema de la creación del derecho (Traducc. Manuel Entenza, Buenos Aires, Ediciones Olejnik).

Hegel, Friedrich y MarX, Karl (1968): Filosofía del derecho (Traducc. Angélica Mendoza de Montero, Buenos Aires, Editorial Claridad), volumen 5.

HUSSERL, EDMUND (1997): Ideas relativas a una fenomenología pura y una filosofía fenomenológica (Traducc. José Gaos, México, Fondo de Cultura Económica).

KANT, IMMANUEL (2007): Fundamentación de la metafísica de las costumbres (Traducc. Manuel García Morente, San Juan de Puerto Rico, Edición digital Pedro M. Rosario Barbosa).

KELSEN, HANS (2009): Teoría pura del derecho, 4a edición (Buenos Aires, Eudeba).

LóPez CALERA, Nicolás (2010): "El interés público: entre la ideología y el derecho", en: Anales de la Cátedra Francisco Suárez - Universidad de Granada (№ 44), pp. 123-148.

MACCORMICK, NeIL (1990): "Los límites de la racionalidad en el razonamiento jurídico", en: Betegón Carrillo, Jerónimo, Derecho y moral, ensayos analíticos (Barcelona, Editorial Ariel), pp. 9-22.

MIR PUIG, SANTIAGO (2006): Estado, pena y delito (Montevideo - Buenos Aires, Editorial B de F).

MoRIN, EdgAR y PAKMAN, MARCELO (1994): Introducción al pensamiento complejo (Barcelona, Editorial Gedisa).

Pastrana Rodríguez, Eduardo (1988): Conciencia y Utopía del hombre americano (Cali, Editorial Poemia).

Pintos de Cea Naharro, JuAn luis (2004): "Inclusión-exclusión. Los imaginarios sociales de un proceso de construcción social”, en: Semata, ciencias sociaies e humanidades (№ 16), pp. 1752.

RADBRUCH, GustaV (1962): Arbitrariedad legal y derecho supralegal (Traducc. M. I. Azareto de Vásquez, Buenos Aires, Editorial Abeledo Perrot).

RANCIÈRE, JACQUES (1995): La mésentente. Politique et philosophie (Paris, Editions Galilée).

RoxIN, CLAUS (2007): La teoría del delito en la discusión actual (Traducc. Manuel Abanto Vásquez, Lima, Editorial Grijley).

SARTRE, JeAN-PAul (1973): El escritor y su lenguaje (Buenos Aires, Editorial Losada, S.A.).

SCHUTZ, AlfRED Y LUCKMANN, THOMAS (2009): Las estructuras del mundo de la vida (Traducc. Néstor Miguez, Buenos Aires, Amorrortu Editores S.A.). 
SICHES, RECASENS (1939): Vida humana, sociedad y derecho: fundamentación de la filosofía del derecho (México, Fondo de Cultura Económica).

SORDÉ, TeRESA Y OJALA, MIKKO (2010): “Actos comunicativos dialógicos y actos comunicativos de poder en la investigación”, en: Revista Signos (Vol. 43, № 2), pp. 377-391.

WROBLEWSKI, JERZY (1988). "Les standards juridiques: problèmes théoriques de la législation et de l'application du droit", en: Revue de la recherche juridique, droit prospectif (№ 4), pp. 847-869.

ZAGREBELSKY, GUSTAVO (1996): La crucifixión y la democracia (Barcelona, Editorial Ariel). Editorial Trotta).

(1997): El derecho dúctil. Ley derechos, justicia (Traducc. Marina Gascón, Madrid, (2011): Historia y constitución (Traducc. Miguel Carbonell, Madrid, Editorial Mínima Trotta). 